\section{General geophysics}

\section{D.H. Tarling}

The Physical Environment. By B.K. Ridley. Pp.236. (Wiley: New York and Chichester, UK, 1979.) £8.50. Palaeomagnetism and Plate Tectonics. By M.W. McElhinny. Pp.357. (Cambridge University Press: Cambridge and New York, 1979.) £7.50.

RIDLEY'S is an interesting little book designed to provide an awareness of the total underlying physical structure of the environment for students of science and engineering. The scientists to whom the book is addressed include social scientists and it therefore uses a minimum of mathematics in its attempt to provide a unified basis for the comprehension of the relationships between astronomy, geology, meteorology and oceanography. The object is therefore laudible but possibly unattainable within such a small compass unless more rigorous mathematical treatment were introduced. This would then probably lose the innumerate section of his audience, exactly those people most likely to benefit from such a synthesis.

The contents are logically organised, starting in outer space and time, before considering the internal and then external features of the Earth. Halfway through there is a more general discussion of the forces of nature, including nuclear reactions, electromagnetic, chemical and gravitational forces, and then a return to the Earth's surface and the forces operating in and on the oceans. The book then begins a return to the outer limits of the Universe, discussing the Earth's atmosphere, solar and stellar processes and finally considers the origin of the Universe, the Solar System and life.

The tour is thus certainly comprehensive and there is little that can be considered either wrong or over-simplified to the extent of giving misleading impressions. It is thus difficult to pin down a feeling of uneasiness. Some of this almost certainly stems from the style, which is generally very readable but tends to launch into purple prose during either introductory or linking sections. Another reason for unease may be the balance given to different aspects. Four pages on Obler's paradox (and extra reference later on) seems excessively unnecessary when inertial waves are not discussed (only inertial oscillations) yet are virtually assumed within the consideration of wind patterns. Other unease arises from inadequate checking. For example, the age of the base of the Cambrian has different values on different pages. Such errors are trivial in terms of the context, but indicate a lack of care in proof-reading. Another unease is the occasional error - the magnetic dipole is "inclined" at $11^{\circ}$ relative to the Earth's axis of rotation, but this state is to be known as declination.

A final cause for unease is the apparent reliance on the London Geological Museum for many of the geologicalgeophysical 'facts' and diagrams. While the Museum's exhibition is an excellent one, it is already out of date in some aspects, such as the presence of a basaltic layer beneath the continental granites - a feature that appears in almost all of the diagrams. It is similarly misleading, or indeed incorrect, to say that volcanic activity at subduction zones is due to the melting of light material thrust into the asthenosphere.

In general, the colour diagrams are excellent - mostly derived from the Geological Museum and NASA - but the black-and-white photographs are poorly reproduced, originally colour prints have poor contrast in grey tones, and it seems unnecessary to actually print the Times weather map with lettering from the reverse side still showing. The omission of the foldout weather satellite photographs could have released money for improving other photographs. However, the diagrams are mostly clear and well produced, as is the book as a whole. There are problems at the end (with answers) for those who wish to test themselves; and there is further reading provided for each chapter, although I see no reason that the reading for chapter 5 is incorporated with that for chapter 4 and there is none for chapter 7 .

Despite the qualms, it is possible to recommend the book for the general student scientist, although it is clearly designed for a British rather than a worldwide market. One hope is that this may be a short print; a revised edition would be likely to be more strongly recommended.
The second book, McElhinny's Palaeomagnetism and Plate Tectonics, is an entirely different proposition. This is aimed at a specific market, the (advanced) undergraduate geologist or geophysicist in particular. When it was originally issued in 1973 , this was an excellent introduction to palaeomagnetism and a review of extant palaeomagnetic data. This "first paperback edition" is, in fact, a straight reprint of the hardback edition. Such a term implies to me that some editing or updating has been undertaken and as this is certainly not the case, the publisher's claim that it is "a review of the state of knowledge in the subject", which was justified in 1973, cannot conceivably be justified in 1979. The data base has expanded severalfold since McElhinny submitted the manuscript in, presumably, 1972. There have also been major advances in our understanding of magnetic processes within rocks, the behaviour of magnetic minerals, the instrumentation to measure either the magnetisation or other magnetic properties, and so forth. It is thus invidious to both the author and the reviewer to comment in detail on how certain aspects no longer correspond with current knowledge or awareness. CUP would have been better advised to issue a revised edition. As it is, this book can still be recommended as highly readable and well presented. The production is good and reasonably durable. It is with sorrow and disappointment that one can no longer give this paperback edition the recommendation which the original hardback deserved so well.

D. H. Tarling is Senior Lecturer in Geophysics at the University of Newcastle-upon-Tyne, UK.

\section{Solid state physics}

\section{W. Cochran}

The Solid State. By H.M. Rosenberg. Second edition. Pp.274. (Clarendon Oxford University Press: Oxford, 1979.) Hardback £5.50; paperback £2.25.

THE first edition of this book appeared in 1975 and I feel sure that it was read and enjoyed by most lecturers in solid-state physics, and that they will have recommended it to their students. It is one of the Oxford Physics Series, which the Editor describes as core texts intended to cover material usually treated in the first year of honours courses in English universities, or in the second year in Scotland. The Editor introduces the book as one which succeeds in capturing the spirit of the stimulating lecture course that Oxford undergraduates have enjoyed for many years from Dr Rosenberg, and goes on to claim that it requires only a fairly basic background in mechanics, electricity and magnetism, and atomic physics, along with relatively intuitive ideas in quantum physics.

The only important difference between the second and first editions is the addition of a fourteenth chapter, on superconductivity. While I liked this chapter as well as any, I fear it will be beyond the scope of students - particularly of materials science and engineering - at the level for which the book is intended. One or two new problems have been added after the earlier chapters, and fourteen after the final one, to give a total of about 120 . Numerical answers are now given where appropriate, although the author admits that he views the ensuing correspondence with some trepidation. A new section has 